\title{
Trapped in the COVID-19 pandemic: The effect of risk concern and emotions on burnout among health care workers
}

\author{
Inês C. Sousa ${ }^{1}$, Teresa Almeida ${ }^{1}$ \& Catarina Correia Leal ${ }^{1}$ \\ ${ }^{1}$ Instituto Universitário de Lisboa (ISCTE-IUL), Business Research Unit (BRU-IUL), Lisboa, Portugal
}

\begin{abstract}
The COVID-19 pandemic poses critical challenges for the health care workers (HCWs) around the world due to the increasing demands imposed on health care systems. This study aims to investigate how risk concern impacts burnout via positive and negative affect. Further, the moderating role of risk exposure (low, medium, and high) in this parallel mediation model is examined. A sample of 257 Portuguese HCWs answered a questionnaire. Structural equation modeling (SEM) analysis was applied. Results showed that risk concern positively influences negative affect - but not positive affect - and, consequently, burnout. Contrary to our expectations, this indirect effect was not greater for individuals in the high-risk group (vs. low-risk group), which can be explained by individual and organizational factors' buffering role. These findings draw healthcare organizations' attention to the hazardous effects of risk concern on HCWs' well-being.
\end{abstract}

Keywords: COVID-19; health care workers; burnout; risk perception; positive affect; negative affect.

Encurralados na pandemia de COVID-19: 0 efeito da preocupação com o risco e das emoções no burnout nos profissionais de saúde: A pandemia de COVID-19 acarreta desafios para os profissionais de saúde em todo o mundo, devido às exigências impostas aos sistemas de saúde. Pretendemos investigar o modo como a preocupação com o risco influencia o burnout via afeto positivo e negativo. 0 papel moderador da exposição ao risco (baixa, média e alta) é também examinado. Uma amostra de 257 profissionais de saúde portugueses respondeu a um questionário. A análise de modelos de equações estruturais foi aplicada. Os resultados mostraram que a preocupação com o risco influencia positivamente o afeto negativo - mas não o positivo - e, consequentemente, o burnout. Este efeito indireto não foi superior para os indivíduos do grupo de alto risco (vs. baixo risco), o que poderá ser explicado por fatores individuais e organizacionais atenuantes. Estas evidências chamam a atenção das organizações de saúde para os efeitos adversos da preocupação com o risco no bem-estar destes profissionais.

Palavras-chave: COVID-19; profissionais de saúde; burnout; perceção de risco; afeto positivo; afeto negativo

The worldwide outbreak known as COVID-19, caused by the Severe Acute Respiratory Syndrome CoronaVirus 2 (SARS-CoV-2), triggered a significant public health concern. In March 2020, the DirectorGeneral of the World Health Organization (WHO) declared COVID-19 a pandemic due to the high transmissibility and lethality of the disease (WHO, 2020).

Despite the social and physical distancing measures aimed at decelerating the disease's spread, WHO advocated the preparation of health facilities and health professionals to cope with the increasing number of COVID-19 patients. Health care workers (HCWs) are in the front line of the outbreak response, dealing with patients (with COVID-19 or other diseases) and their families, and therefore facing a considerably increased risk of becoming infected with COVID-19 (Bielicki et al., 2020).

Thus, the purpose of this study was to understand how HCWs' concern about contracting COVID-19 affected their emotions and consequently impacted their burnout levels. To sustain our hypotheses, we have drawn on one conservation of resources theory underlying mechanism, i.e., energy depletion (Hobfoll et al., 2018). In our study, the energy depletion mechanism may be crucial to explain the effort and resources spent by HCWs during this high-stress situation and its impacts on affectivity and burnout.

A sample of Portuguese HCWs was chosen due to the high-pitched number of patients of COVID-19 that the country registered, which demanded extra efforts from the Portuguese health care system. According to the Portuguese Directorate-General of Health and the Portuguese Ministry of Health, until the end of June 2020, the country registered 42,523 confirmed cases of COVID-19, from which a total of 1,579 deaths and 27,798 recovered cases were registered (Direção-Geral da Saúde, 2020). Adding to this, HCWs

${ }_{1}^{1}$ Correspondence address: Inês Carneiro e Sousa, Business Research Unit (BRU-IUL), Instituto Universitário de Lisboa (ISCTE-IUL), Av. das Forças Armadas, 1649-026 Lisboa, Portugal E-mail: ines_carneiro_sousa@iscte-iul.pt 
comprised a significant proportion of the people who contracted the disease. Indeed, according to recent reports, in Portugal, until the $24^{\text {th }}$ of July, $8.25 \%$ of the infected were healthcare professionals (Jornal Médico, 2020).

The COVID-19 pandemic, like other pandemics that have affected the world (e.g., Ebola), has demanded additional efforts from HCWs that, unlike other professionals, were required to continue working to assist all the infected. By doing so, these professionals were much more susceptible to have contact with the COVID-19, putting their health at risk for everyone else's. Hewlett and Hewlett (2005) suggested that this constant exposure to risk may increase HCWs' levels of fear and insecurity about being infected.

In this highly stressful pandemic context, our results have significant contributions. Specifically, findings inform HCWs, health care managers, and organizations about the harmful effects of risk concern on negative affect and burnout.

\section{THEORETICAL BACKGROUND}

\section{The impact of burnout in the healthcare context}

As defined by Kristensen et al. (2005, p. 197), work-related burnout is the "degree of physical and psychological fatigue and exhaustion that the person perceives as related to his/her work." Burnout has been widely studied amongst HCWs and carries significant consequences to workers (e.g., Munyon et al., 2009), the organization (e.g., Leiter \& Maslach, 2009), and patients (e.g., Dewa et al., 2017). Ehrlich et al. (2020) highlight the susceptibility of HCWs in the context of COVID-19, which is in line with Jalili et al. (2020) and Barello et al. (2020) findings on burnout prevalence among HCWs during this period.

Occupational stress, a well-established antecedent of burnout, is often experienced by HCWs and might have been intensified during the pandemic (Sultana et al., 2020). COVID-19 is responsible for an important psychological impact in this population, where anxiety and stress can be aggravated. This can be explained by the still hidden and uncontrollable nature of this disease, where there is still limited knowledge but a significant health impact (Jalili et al., 2020).

\section{Risk concern as a predictor of burnout}

As mentioned before, risk concern is expected to be related to enhanced strain among HCWs during this pandemic (Sultana et al., 2020). We draw upon the conservation of resources (COR) framework (Hobfoll et al., 2018). This framework outlines how individuals in their personal and professional lives endeavor to attain, assemble, and protect valued resources (e.g., health and well-being) to avoid strain. Employees may experience strain when their available resources are scarce, i.e., because they are threatened or lost, making them incapable of coping effectively with demands, especially in contexts where these are highly imposed (Hobfoll et al., 2018).

The use of this theoretical framework to explain our rationale is justified by several reasons. First, Portugal has recently overcome a severe economic crisis, and it is known that employees from countries that experience this kind of crisis tend to develop higher levels of burnout and negative affect due to the persistent perception of losing important resources, such as their jobs or work stability (Ferreira et al., 2019). Second, the loss and gain of resources are central in high-stress situations, where demands tend to increase (Alarcon, 2011). Thus, the dramatic increase in labor requirements imposed by the COVID-19 pandemic and the heightened risk perceptions associated with it may have potentiated resource losses (e.g., health and well-being). In this study, we conceptualize the risk concern of contracting COVID-19 as a stressor that may increase burnout levels. Thus, we propose that:

Hypothesis 1. Risk concern is positively related to burnout.

\section{The mediation role of affect}

Risk perception comprises two components: cognitive and affective (Sjöberg, 1998). The former is related to the individual's perceived likelihood of experiencing a dangerous event, and the latter refers to how much they worry about it (Rundmo, 2000). The emotional component holds a critical role due to the level of uncertainty caused by the COVID-19 pandemic. Accordingly, Freeston et al. (2020) describe that this pandemic may contribute to uncertainty distress, "the subjective negative emotions experienced in response to the as yet unknown aspects of a given situation" (p. 1). This is in line with Son et al. (2019) work that describes emotional arousal as a consequence of risk appraisal.

Affective states hold a positive and negative nature. Positive affect expresses enthusiasm, activeness, and alertness, while negative affect expresses subjective distress (Galinha et al., 2014). Both negative and positive affect are associated with subjective health (Benyamini et al., 2000). Moreover, Little et al. (2007) 
findings show that negative affect is positively associated with burnout, while positive affect is negatively associated with it, which was also found in a study with HCWs (Montero-Marin et al., 2015).

From what has been described, burnout can be conceived as a product of work demands and a lack of resources (Munyon et al., 2009). Therefore, the COR theory (Hobfoll et al., 2018) may illustrate this process. Accordingly, risk concern overloads HCWs, contributing to the loss of mental resources expressed by low levels of positive affect and high levels of negative affect - and burnout. Therefore, we posit that:

Hypothesis 2. Positive affect mediates the positive relationship between risk concern and burnout. Hypothesis 3: Negative affect mediates the positive relationship between risk concern and burnout.

\section{The moderator role of risk exposure}

As mentioned, risk concern may increase burnout, and emotions play an essential role in this process (e.g., Montero-Marin et al., 2015). However, these effects may vary depending on the level of exposure to the risk. As humans, we are provided with mechanisms that prevent us from harmful and dangerous situations. Neuberg et al. (2011) proposed two threat-management systems (self-protection and disease avoidance) that activate affective, cognitive, and behavioral responses. Broadly, these mechanisms will operate to decrease risk, which, in most cases, means that once a threat is perceived, it will be avoided. Some findings are in line with this framework, showing how risk perception may decrease the level of risk exposure (Stewart-Taylor \& Cherrie, 1998).

HCWs are frontline players in this pandemic, which may increase their levels of risk concern (Hewlett \& Hewlett, 2005). However, withdrawing from their job is not a solution. Moreover, depending on the specific position, some HCWs are highly exposed to risk, regardless of concern levels. We argue that not being able to behave according to risk appraisal may provide additional strain and excessive resource consumption, resulting in higher burnout levels. Specifically, we propose that:

Hypothesis 4. The level of risk exposure will moderate all of the hypothesized relationships such that the effects will be stronger for individuals who report high levels of exposure (vs. low levels).

\section{METHOD}

\section{Procedure and Participants}

Data were collected through an online questionnaire during May and June of 2020, disseminated through the research team's networks. Informed consent was presented to participants at the beginning of the questionnaire.

The sample consists of 257 HCWs, aged between 21 and $65(M=36.80, S D=10.47)$. Most participants were female (86.8\%), completed a bachelor's degree $(63.8 \%)$, and about $70 \%$ worked in the organization for 15 years or less. Among the participants, 39.2\% were nurses, 30.2\% were senior diagnostic and therapeutic technicians (TSDTs), and $25.2 \%$ worked in a private health unit. Individuals were categorized into three groups according to their perceived level of exposure to COVID-19: low, medium, and high exposure. Table 1 presents the participants' characteristics by level of exposure.

\section{Measures}

All participants were fluent in Portuguese, which required the translation/back-translation procedure (Brislin, 1970; van de Vijver \& Hambleton, 1996). The first stage involved translating the items from the source language (i.e., English) to the target language (i.e., Portuguese). Then a blind back-translation was performed by an independent researcher. This version was compared to the original version and reviewed by a bilingual researcher who suggested small modifications. Given that the positive and negative affect scale was already adapted and validated for Portugal (Galinha et al., 2014), it was not included in the translation process. 
Table 1. Participants' characteristics by level of risk exposure.

\begin{tabular}{|c|c|c|c|}
\hline & Low exposurea & Medium exposureb & High exposurec \\
\hline \multicolumn{4}{|l|}{ Age } \\
\hline \multirow[t]{2}{*}{$M(S D)$} & $37.8(12.3)$ & $35.5(9.5)$ & $37.4(9.3)$ \\
\hline & $\%$ & $\%$ & $\%$ \\
\hline \multicolumn{4}{|l|}{ Sex } \\
\hline Female & 84.7 & 89.7 & 85.3 \\
\hline Male & 15.3 & 10.3 & 14.7 \\
\hline \multicolumn{4}{|l|}{ Education } \\
\hline High school & 1.2 & 4.1 & 8.0 \\
\hline Bachelor's degree & 63.5 & 63.9 & 64.0 \\
\hline Graduate degree & 35.3 & 32.0 & 28.0 \\
\hline \multicolumn{4}{|l|}{ Professional category } \\
\hline TSDT & 41.7 & 27.8 & 20.3 \\
\hline Nurse & 32.1 & 38.1 & 48.6 \\
\hline Physician & 9.5 & 12.4 & 8.1 \\
\hline Pharmaceutical & 9.5 & 9.3 & 6.8 \\
\hline Other professionals & 7.2 & 12.4 & 16.2 \\
\hline \multicolumn{4}{|l|}{ Supervisor role } \\
\hline Yes & 22.4 & 15.5 & 14.7 \\
\hline No & 77.6 & 84.5 & 85.3 \\
\hline \multicolumn{4}{|l|}{ Organizational tenure } \\
\hline$\leq 5$ years & 50.6 & 48.5 & 41.3 \\
\hline $6-15$ years & 22.4 & 22.7 & 24.0 \\
\hline $16-25$ years & 15.3 & 23.7 & 29.3 \\
\hline$>25$ years & 11.7 & 5.1 & 5.4 \\
\hline \multicolumn{4}{|l|}{ Type of organization } \\
\hline Central hospital & 15.5 & 22.9 & 31.0 \\
\hline District hospital & 4.8 & 13.5 & 29.7 \\
\hline Primary health care & 7.1 & 11.4 & 8.1 \\
\hline Public health unit & 3.6 & 2.1 & 4.1 \\
\hline Private hospital & 10.7 & 9.4 & 6.8 \\
\hline Private health unit & 32.1 & 29.2 & 12.1 \\
\hline Pharmacy & 8.3 & 9.4 & 4.1 \\
\hline Residential care & 17.9 & 2.1 & 4.1 \\
\hline
\end{tabular}

Note. a $N=85 ;$ b $N=97 ;{ }^{\text {c }} N=75$.

Risk perception. Risk perception questions were adapted from Sridhar et al. (2016) and include risk exposure and risk concern. Participants were asked to indicate their perceived level of exposure to COVID19 on a scale from 1 - no contact to 7 - full-time contact (i.e., "Does your work involve direct contact with patients with COVID-19?"). Risk concern was measured through one question: "To what extent are you concerned that you might contract COVID-19?", answered on a scale from 1 - not at all to 7 - very much concerned.

Positive and negative affect. Positive and negative affect were assessed through the short version of PANAS (PANAS-VRP) (Galinha et al., 2014). Participants answered 10 items about how often they had experienced a specific emotion since the beginning of the pandemic situation on a scale from 1 (not at all) to 5 (extremely). The positive affect subscale included five items (e.g., enthusiastic, active), and the negative affect subscale encompassed five items (e.g., nervous, scared). Both subscales showed very good internal consistency ( $\alpha=.85$ for each dimension). 
Burnout. Burnout was assessed using the 7-item Copenhagen Burnout Inventory (Kristensen et al., 2005). Participants answered on a 5-point scale ranging from 1 - never/almost never to 5 - always. A sample item is "Is your work emotionally exhausting?". The scale revealed excellent internal reliability $(\alpha=.90)$.

Controls. Age (in years) was used as a control variable since previous literature found that it is associated with burnout (e.g., Munyon et al., 2009). Also, supervisors' support was identified as a predictor of burnout among HCWs (e.g., Pisanti et al., 2011), and therefore it was controlled in this study.

\section{Measurement model and common method bias}

A Confirmatory Factor Analysis (CFA) for the total sample was conducted in AMOS v. 25. The measurement model showed a good fit to the data, $\chi^{2}(111)=217.62, p<.001, \chi^{2} / d f=1.961, \mathrm{CFI}=.96$, TLI $=.95$, RMSEA $=.06$, SRMR $=.07$ (Hair et al., 2010). As shown in Table 2, this three-factor measurement model yielded a better fit than all the alternative models.

Reliability, convergent, and discriminant validity of the measurement model were assessed and are summarized in Table 3. All constructs showed high internal consistency as Cronbach's alphas ranged between .85 and .90, and composite reliability (CR) indices exceeded .70 (Hair et al., 2010). In addition, the average variance extracted (AVE) values were equal to or above the threshold value of .50 (Hair et al., 2010). Therefore, the latent variables meet the requirements of convergent validity.

Table 2. Fit indices for measurement model comparisons

\begin{tabular}{lccccc}
\hline Models & $\begin{array}{l}\text { Three-Factor - Model 1 } \\
\text { (Full measurement } \\
\text { model) }\end{array}$ & Model 2 a) & Model 3 b) & Model 4 c) & $\begin{array}{c}\text { Model 5 d) } \\
\text { (Harman's Single Factor) }\end{array}$ \\
\hline$\chi^{2}(\mathrm{df})$ & $217.62(111)$ & $457.92(113)$ & $384.96(113)$ & $563.98(113)$ & $731.66(114)$ \\
$\chi^{2} / \mathrm{df}$ & 1.961 & 4.052 & 3.407 & 4.991 & 6.418 \\
CFI & .96 & .86 & .88 & .81 & .74 \\
TLI & .95 & .83 & .86 & .77 & .69 \\
RMSEA & .07 & .11 & .10 & .13 & .15 \\
SRMR & .06 & .14 & .10 & .08 & .12 \\
$\Delta \chi^{2}$ & & $240.30(2)^{* * *}$ & $167.34(2)^{* * *}$ & $346.36(2)^{* * *}$ & $514.04(3)^{* * *}$ \\
\hline
\end{tabular}

Note. $\mathrm{N}=257 ; \chi^{2}$ - chi-square; $\mathrm{df}$ - degrees of freedom; $\chi^{2} / \mathrm{df}$ - normed chi-square; CFI - comparative fit index; TLI - Tucker-Lewis index; RMSEA - root mean square error of approximation; SRMR - standardized root mean square residual; $\Delta \chi^{2}$ - chi-square difference.

a) Positive affect and Negative affect combined into a single factor.

b) Positive affect and Burnout combined into a single factor.

c) Negative affect and Burnout combined into a single factor.

d) The three factors combined into a single factor.

${ }^{* * *} p<.001$

As shown in Table 3, the AVE of each construct's square root is greater than the inter-construct correlations, which fulfilled the Fornell-Larcker criterion (Fornell \& Larcker, 1981). The AVE values were also greater than the maximum shared variance (MSV) (Hair et al., 2010). Moreover, the heterotraitmonotrait (HTMT) ratio of correlations values ranged between .35 and .68, below the threshold of .85 (Henseler et al., 2015). Thus, discriminant validity is reached in this study.

Table 3. Discriminant and convergent validity of latent constructs

\begin{tabular}{lcccccc}
\hline Constructs & CR & AVE & MSV & $\mathbf{1}$ & $\mathbf{2}$ & $\mathbf{3}$ \\
\hline 1. Positive affect & .83 & .50 & .24 &. $\mathbf{7 0}$ & & \\
2. Negative affect & .85 & .56 & .34 & $-.28^{* * *}$ &. $\mathbf{7 5}$ & \\
3. Burnout & .90 & .57 & .34 & $-.49^{* * *}$ & $.58^{* * *}$ & $\mathbf{. 7 6}$ \\
\hline
\end{tabular}

Note. CR - composite reliability; AVE - average variance extracted; MSV - maximum shared variance

The square root of the AVE is depicted in boldface on the diagonal. Off-diagonal elements are the correlations among latent constructs. 
Harman's single-factor test was conducted to address common method variance concerns (Podsakoff et al., 2003). As shown in Table 2, a single-factor model showed a poor fit to the data.

Finally, to detect multicollinearity, tolerance and variance inflation factor (VIF) values were calculated using SPSS v. 26. Tolerance values ranged between .69 and $.92(>.10)$, whereas the VIF values ranged from 1.09 to $1.45(<5)$, suggesting that there are no multicollinearity problems in the model (Hair et al., 2010).

\section{Measurement invariance}

A multi-group confirmatory factor analysis (MCFA) was then used to assess the configural, metric and scalar invariance of the three groups: low, medium, and high exposure to COVID-19 (Vandenberg \& Lance, 2000). The measurement model reached a good fit, $\chi^{2}(333)=458.83, p<.001, \chi^{2} / d f=1.378, \mathrm{CFI}=.95$, $\mathrm{TLI}=.93$, RMSEA $=.04$, SRMR $=.09$. Thus, configural invariance was established.

Full metric invariance was assessed by comparing the unconstrained model (i.e., free estimates) with the constrained model (i.e., factor loadings constrained to be equal across groups). Results indicate that there is full metric invariance $\left(\Delta \chi^{2}(28)=28.98, p>.05\right)$. Finally, scalar invariance was tested by maintaining the metric invariance model's restrictions and constraining observed variables' intercepts on their latent factor. This model shows scalar invariance $\left(\Delta \chi^{2}(62)=65.23, p>.05\right)$. These findings establish measurement invariance, justifying the examination of differences across levels of risk exposure.

\section{RESULTS}

The descriptive statistics of variables in the study are presented in Table 4. For the three levels of exposure, the strongest correlations were found between negative affect and risk concern $\left(r_{\text {low }}=.44, p<.001 ; r_{\text {med }}=\right.$ $\left..53, p<.001 ; r_{\text {high }}=.48, p<.001\right)$, and negative affect and burnout $\left(r_{\text {low }}=.57, p<.001 ; r_{\text {med }}=.67, p<.001\right.$; $\left.r_{\text {high }}=.43, p<.001\right)$.

Table 4. Descriptive statistics of variables in the study

\begin{tabular}{lcccccccc}
\hline & \multicolumn{2}{c}{ Total sample $^{\mathbf{a}}$} & \multicolumn{2}{c}{ Low exposureb $^{\mathbf{b}}$} & \multicolumn{2}{c}{ Medium exposurec $^{\mathbf{c}}$} & \multicolumn{2}{c}{ High exposured $^{\mathbf{d}}$} \\
\hline Variable & $M$ & $S D$ & $M$ & $S D$ & $M$ & $S D$ & $M$ & $S D$ \\
\hline Risk concern & 4.82 & 1.69 & 3.98 & 1.63 & 5.00 & 1.56 & 5.55 & 1.54 \\
Positive affect & 3.12 & 0.77 & 3.26 & 0.83 & 2.98 & 0.76 & 3.15 & 0.68 \\
Negative affect & 2.47 & 0.86 & 2.22 & 0.75 & 2.60 & 0.88 & 2.59 & 0.90 \\
Burnout & 3.21 & 0.77 & 2.90 & 0.76 & 3.32 & 0.76 & 3.39 & 0.72 \\
Age & 36.80 & 10.47 & 37.81 & 12.31 & 35.45 & 9.45 & 37.40 & 9.32 \\
Supervisor's support & 3.91 & 1.56 & 4.30 & 1.59 & 3.56 & 1.50 & 3.92 & 1.52 \\
\hline
\end{tabular}

Note. ${ }^{\text {a }} \mathrm{N}=257 ;{ }^{\mathrm{b}} \mathrm{N}=85 ;{ }^{\mathrm{c}} \mathrm{N}=97 ;{ }^{\mathrm{d}} \mathrm{N}=75$.

\section{Structural model}

A three-group structural equation modeling (SEM) was conducted in AMOS to investigate if the level of risk exposure impacted the proposed model. The structural model showed an acceptable fit, $\chi^{2}(468)=707.70$, $p<.001, \chi^{2} / d f=1.512$, CFI $=.91$, TLI $=.88$, RMSEA $=.05$, SRMR $=.10$. Results are illustrated in Table 5. Hypothesis 1 stated that risk concern would positively correlate with burnout, which was supported by the findings. 
Table 5. Multi-group SEM results for total sample and low, medium, and high levels of risk exposure

\begin{tabular}{|c|c|c|c|c|c|c|c|c|c|c|c|c|}
\hline & \multicolumn{3}{|c|}{ Total samplea } & \multicolumn{3}{|c|}{ Low exposureb } & \multicolumn{3}{|c|}{ Medium exposurec } & \multicolumn{3}{|c|}{ High exposured } \\
\hline & $\mathrm{B}(\mathrm{SE})$ & $t$ & $95 \% \mathrm{CI}$ & $\mathrm{B}(\mathrm{SE})$ & $t$ & $95 \% \mathrm{CI}$ & $\mathrm{B}(\mathrm{SE})$ & $t$ & $95 \% \mathrm{CI}$ & $\mathrm{B}(\mathrm{SE})$ & $t$ & $95 \% \mathrm{CI}$ \\
\hline \multicolumn{13}{|l|}{ Mediation model } \\
\hline \multicolumn{13}{|l|}{ Total effect } \\
\hline $\mathrm{RC} \rightarrow$ Burnout & $.13(.03)^{* * *}$ & 4.13 & {$[.08, .19]$} & $.16(.06)^{* *}$ & 2.78 & {$[.07, .26]$} & $.09(.05)^{\dagger}$ & 1.83 & {$[.01, .16]$} & $.05(.05)$ & 0.92 & {$[-.03, .14]$} \\
\hline \multicolumn{13}{|l|}{ Direct effect } \\
\hline $\mathrm{RC} \rightarrow$ Burnout & $.01(.03)$ & 0.19 & {$[-.05, .06]$} & $.02(.06)$ & 0.32 & {$[-.07, .12]$} & $-.08(.04)^{\dagger}$ & -1.77 & {$[-.15,-.01]$} & $.01(.07)$ & 0.14 & {$[-.11, .12]$} \\
\hline $\mathrm{RC} \rightarrow \mathrm{PA}$ & $-.03(.03)$ & -1.19 & {$[-.08, .01]$} & $-.09(.05)^{*}$ & -1.94 & {$[-.18,-.03]$} & $-.05(.04)$ & -1.20 & {$[-.13, .01]$} & $.09(.07)$ & 1.34 & {$[.00, .23]$} \\
\hline $\mathrm{RC} \rightarrow \mathrm{NA}$ & $.25(.03)^{* * *}$ & 7.75 & {$[.20, .30]$} & $.23(.06)^{* * *}$ & 4.16 & {$[.14, .32]$} & $.27(.06)^{* * *}$ & 4.23 & {$[.15, .37]$} & $.26(.05)^{* * *}$ & 4.96 & {$[.18, .35]$} \\
\hline PA $\rightarrow$ Burnout & $-.40(.08)^{* * *}$ & -5.00 & {$[-.53,-.27]$} & $-.44(.19)^{*}$ & -2.37 & {$[-.75,-.17]$} & $-.26(.10)^{* *}$ & -2.63 & {$[-.43,-.11]$} & $-.51(.27)^{* *}$ & -1.94 & {$[-.98,-.26]$} \\
\hline NA $\rightarrow$ Burnout & $.46(.09)^{* * *}$ & 5.35 & {$[.33, .60]$} & $.44(.17)^{* *}$ & 2.66 & {$[.18, .71]$} & $.55(.12)^{* * *}$ & 4.76 & {$[.37, .75]$} & $.36(.21)^{\dagger}$ & 1.68 & {$[.01, .70]$} \\
\hline \multicolumn{13}{|l|}{ Indirect effects } \\
\hline $\mathrm{RC} \rightarrow \mathrm{PA} \rightarrow$ Burnout & $.01(.01)$ & 1.18 & {$[.00, .03]$} & $.04(.03)$ & 1.54 & {$[.01, .10]$} & $.01(.01)$ & 1.17 & {$[.00, .04]$} & $-.05(.04)$ & -1.23 & {$[-.15, .00]$} \\
\hline $\mathrm{RC} \rightarrow \mathrm{NA} \rightarrow$ Burnout & $.11(.02)^{* * * *}$ & 4.91 & {$[.08, .16]$} & $.10(.05)^{* * *}$ & 2.17 & {$[.04, .20]$} & $.15(.04)^{* * *}$ & 3.44 & {$[.09, .23]$} & $.09(.06)^{\dagger}$ & 1.61 & {$[.01, .20]$} \\
\hline
\end{tabular}

Note. ${ }^{\text {a }} \mathrm{N}=257 ;{ }^{\mathrm{b}} \mathrm{N}=85 ; \mathrm{c} \mathrm{N}=97 ; \mathrm{d} \mathrm{N}=75$. Unstandardized coefficients are reported. All estimates were tested for significance using bias-corrected (BC) confidence interval from

5,000 bootstrap samples.

$\mathrm{RC}=$ risk concern; $\mathrm{PA}=$ positive affect; $\mathrm{NA}=$ negative affect

${ }^{\dagger} p<.10{ }^{*} p<.05{ }^{* *} p<.01{ }^{* * *} p<.001$ 
The second hypothesis, proposing that positive affect would mediate the relationship between risk concern and burnout, was not supported. Hypothesis 3 claimed that negative affect would mediate the relationship between risk concern and burnout. The findings support this hypothesis, as shown in Table 5.

Finally, the fourth hypothesis proposed that previously hypothesized relationships would be moderated by the level of risk exposure, such that the effects would be stronger for individuals who perceive high risk. A pairwise parameter comparison was conducted to compare the magnitude of coefficients from the multi-group analysis. Contrary to our expectations, there were no significant differences between low and high-risk groups in the risk concern-burnout relationship $(z=-.173, p>.05)$. Also, the indirect effect of risk concern on burnout via negative affect was not statistically different for these two groups $(z=-.332, p>.05)$. Thus, hypothesis 4 was not supported.

\section{DISCUSSION}

This study investigated the impact of risk concern on burnout of HCWs during the COVID-19 pandemic and the mediation of positive and negative affect in this relationship. Further, this paper examined the moderation role of risk exposure in this parallel mediation model.

Hypotheses 1 and 3 were supported by the findings, consistent with previous literature on burnout (e.g., Little et al., 2007; Montero-Marin et al., 2015). These findings are of critical importance once they offer both theoretical and practical contributions. They are especially important since a second wave of COVID19 constitutes a looming threat to health care systems (Leung et al., 2020). First, our study shows that a critical contextual stressor (i.e., risk concern) increases burnout levels among HCWs in the specific context of COVID-19 (H1). This is critical because HCWs are pivotal players in fighting the pandemic. Thus, it is not overstated to claim that HCWs' well-being may have an essential and systemic impact in society, making clear the urgency to implement strategies designed to decrease risk concern and its effect on burnout. The SARS-CoV-2 virus spreads through close contact (WHO, 2020). Therefore, we argue that risk concern can be reduced if one can use protective barriers, particularly in HCWs work settings where it is impossible to ensure physical distancing. An example of a highly valued strategy is personal protective equipment delivery and training (Carvalho et al., 2019; Wang et al., 2020).

Second, results regarding the mediation of negative affect (H3) provide empirical evidence to expand the COR theory (Hobfoll et al., 2018). Accordingly, within the pandemic context (i.e., high demanding context), HCWs' risk concern (that creates an overloaded mental state) produces negative affect (i.e., loss of resources), giving rise to burnout. Again, these results suggest that organizations should implement an integrated strategy to buffer the negative potential of risk concern on negative affect and burnout. Within this specific context, HCWs cannot decide to skip work to avoid the source of stress, and for this reason, they need to learn how to face and manage this contextual threat. Therefore, this study aims to draw organizations' attention to the relevance of considering emotion regulation and stress management training programs (e.g., Hersch et al., 2016).

Hypothesis 2 was not verified as risk concern did not influence positive affect, which means that individuals do not experience fewer positive emotions despite being concerned with becoming infected with COVID-19. The lack of support for this hypothesis can be explained by the buffering role of other workrelated factors, such as the existence of a safety climate (i.e., safety policies, procedures, practices, and behaviors in the workplace), and personal factors (e.g., social support outside work) (e.g., McCaughey et al., 2013).

Hypothesis 4 was not supported as both direct and indirect (via negative affect) effects were not stronger for the high-risk group. These results can have two main explanations. First, when perceiving risky situations, workers may engage in problem-solving adaptive strategies such as wearing protective equipment (Arezes \& Miguel, 2005), which may impact their vulnerability to experience burnout. Second, higher levels of risk exposure may produce habituation (Barnett \& Breakwell, 2001), which may explain why those reporting higher risk exposure levels do not report more burnout due to risk concern.

In conclusion, our findings disclose the reality of HCWs in a pandemic context. Despite its contributions to understanding how COVID-19 impacts HCWs' well-being, our study is not without limitations. First, this was a cross-sectional study using self-reported measures. Also, we point to our sample size as a limitation. Hence, future research should use longitudinal designs and broader samples to enhance study findings' generalization. Second, the convenience sample of this study was collected through a snowball approach. However, we have applied this sampling method due to the population's specificities (i.e., health care sector) we intended to study (Babbie, 2014). 


\section{REFERENCES}

Alarcon, G. M. (2011). A meta-analysis of burnout with job demands, resources, and attitudes. Journal of Vocational Behavior, 79(2), 549-562. https://doi.org/10.1016/j.jvb.2011.03.007

Arezes, P. M., \& Miguel, A. S. (2005). Hearing protection use in industry: The role of risk perception. Safety Science, 43(4), 253-267. https://doi.org/10.1016/j.ssci.2005.07.002

Babbie E. R. (2014). The practice of social research. Nelson Education.

Barello, S., Palamenghi, L., \& Graffigna, G. (2020). Burnout and somatic symptoms among frontline healthcare professionals at the peak of the Italian COVID-19 pandemic. Psychiatry Research, 290, 113129. https://doi.org/10.1016/j.psychres.2020.113129

Barnett, J., \& Breakwell, G. M. (2001). Risk perception and experience: Hazard personality profiles and individual differences. Risk Analysis, 21(1), 171-178. https://doi.org/10.1111/0272-4332.211099

Benyamini, Y., Idler, E. L., Leventhal, H., \& Leventhal, E. A. (2000). Positive affect and function as influences on self-assessments of health: Expanding our view beyond illness and disability. The Journals of Gerontology Series B: Psychological Sciences and Social Sciences, 55(2), 107-116. https://doi.org/10.1093/geronb/55.2.P107

Bielicki, J. A., Duval, X., Gobat, N., Goossens, H., Koopmans, M., Tacconelli, E., \& van der Werf, S. (2020). Monitoring approaches for healthcare workers during the COVID-19 pandemic. The Lancet Infectious Diseases, 20(10), e261-267. https://doi.org/10.1016/S1473-3099(20)30458-8

Brislin, R. W. (1970). Back-translation for cross-cultural research. Journal of Cross-Cultural Psychology, 1(3), 185-216. https://doi.org/10.1177/135910457000100301

Carvalho, E., Castro, P., León, E., Del Río, A., Crespo, F., Trigo, L., et al. (2019). Multi-professional simulation and risk perception of health care workers caring for Ebola-infected patients. Nursing in Critical Care, 24(5), 256-262. https://doi.org/10.1111/nicc.12396

Dewa, C. S., Loong, D., Bonato, S., \& Trojanowski, L. (2017). The relationship between physician burnout and quality of healthcare in terms of safety and acceptability: a systematic review. BMJ Open, 7(6):e015141. https://doi.org/10.1136/bmjopen-2016-015141

Direção-Geral da Saúde. (2020). Novo coronavírus COVID-19: Relatório de situação n. 121 [New coronavirus COVID-19: Situation report No. 121]. Ministério da Saúde. https://covid19.min-saude.pt/wpcontent/uploads/2020/07/121_DGS_boletim_20200701_02.pdf

Ehrlich, H., McKenney, M., \& Elkbuli, A. (2020). Protecting our healthcare workers during the COVID-19 pandemic. The American Journal of Emergency Medicine, 38(7), 1527-1528. https://doi.org/10.1016/j.ajem.2020.04.024

Ferreira, A. I., da Costa Ferreira, P., Cooper, C. L., \& Oliveira, D. (2019). How daily negative affect and emotional exhaustion correlates with work engagement and presenteeism-constrained productivity. International Journal of Stress Management, 26(3), 261-271. https://doi.org/10.1037/str0000114

Fornell, C., \& Larcker, D. F. (1981). Evaluating structural equation models with unobservable variables and measurement error. Journal of Marketing Research, 18(1), 39-50. https://doi.org/10.1177/002224378101800104

Freeston, M., Tiplady, A., Mawn, L., Bottesi, G., \& Thwaites, S. (2020). Towards a model of uncertainty distress in the context of Coronavirus (Covid-19). The Cognitive Behaviour Therapist, 13(e31), 1-15. https://doi.org/10.1017/S1754470X2000029X

Galinha, I. C., Pereira, C. R., \& Esteves, F. (2014). Versão reduzida da escala portuguesa de afeto positivo e negativo - PANAS-VRP: Análise fatorial confirmatória e invariância temporal. Psicologia, 28(1), 5365.

Hair, J. F., Black, W. C., Babin, B. J., \& Anderson, R. E. (2010). Multivariate data analysis: A global perspective (7th ed.). Prentice Hall.

Henseler, J., Ringle, C. M., \& Sarstedt, M. (2015). A new criterion for assessing discriminant validity in variance-based structural equation modeling. Journal of the Academy of Marketing Science, 43(1), 115-135. https://doi.org/10.1007/s11747-014-0403-8

Hersch, R. K., Cook, R. F., Deitz, D. K., Kaplan, S., Hughes, D., Friesen, M. A., et al. (2016). Reducing nurses' stress: A randomized controlled trial of a web-based stress management program for nurses. Applied Nursing Research, 32, 18-25. https://doi.org/10.1016/j.apnr.2016.04.003

Hewlett, B. L., \& Hewlett, B. S. (2005). Providing care and facing death: Nursing during Ebola outbreaks in central Africa. Journal of Transcultural Nursing, 16(4), 289-297. https://doi.org/10.1177/1043659605278935

Hobfoll, S. E., Halbesleben, J., Neveu, J. P., \& Westman, M. (2018). Conservation of resources in the organizational context: The reality of resources and their consequences. Annual Review of 
Organizational Psychology and Organizational Behavior, 5, 103-128. https://doi.org/10.1146/annurev-orgpsych-032117-104640

Jalili, M., Niroomand, M., Hadavand, F., Zeinali, K., \& Fotouhi, A. (2020). Burnout among healthcare professionals during COVID-19 pandemic: A cross-sectional study. medRxiv. https://doi.org/10.1101/2020.06.12.20129650

Jornal Médico. (2020, July 24). Covid-19: Maioria dos 4.114 profissionais de saúde infetados já recuperou [Covid-19: Majority of 4,114 infected health professionals has recovered]. https://www.jornalmedico.pt/atualidade/39378-covid-19-maioria-dos-4-114-profissionais-desaude-infetados-ja-recuperou.html

Kristensen, T. S., Borritz, M., Villadsen, E., \& Christensen, K. B. (2005). The Copenhagen Burnout Inventory: A new tool for the assessment of burnout. Work \& Stress, 19(3), 192-207. https://doi.org/10.1080/02678370500297720

Leiter, M. P., \& Maslach, C. (2009). Nurse turnover: the mediating role of burnout. Journal of Nursing Management, 17(3), 331-339. https://doi.org/10.1111/j.1365-2834.2009.01004.x

Leung, K., Wu, J. T., Liu, D., \& Leung, G. M. (2020). First-wave COVID-19 transmissibility and severity in China outside Hubei after control measures, and second-wave scenario planning: a modelling impact assessment. The Lancet, 395(10233), 1382-1393. https://doi.org/10.1016/S0140-6736(20)307467

Little, L. M., Simmons, B. L., \& Nelson, D. L. (2007). Health among leaders: Positive and negative affect, engagement and burnout, forgiveness and revenge. Journal of Management Studies, 44(2), 243-260. https://doi.org/10.1111/j.1467-6486.2007.00687.x

McCaughey, D., DelliFraine, J. L., McGhan, G., \& Bruning, N. S. (2013). The negative effects of workplace injury and illness on workplace safety climate perceptions and health care worker outcomes. Safety Science, 51(1), 138-147. https://doi.org/10.1016/j.ssci.2012.06.004

Montero-Marin, J., Tops, M., Manzanera, R., Piva Demarzo, M. M., Alvarez de Mon, M., \& García-Campayo, J. (2015). Mindfulness, resilience, and burnout subtypes in primary care physicians: The possible mediating role of positive and negative affect. Frontiers in Psychology, 6:1895. https://doi.org/10.3389/fpsyg.2015.01895

Munyon, T. P., Breaux, D. M., \& Perrewé, P. L. (2009). Implications of burnout for health professionals. In A. G. Antoniou, C. L. Cooper, G. P. Chrousos, C. D. Spielberger, \& M. W. Eysenck (Eds.), Handbook of managerial behavior and occupational health (pp. 264-277). Edward Elgar.

Neuberg, S. L., Kenrick, D. T., \& Schaller, M. (2011). Human threat management systems: Self-protection and disease avoidance. Neuroscience \& Biobehavioral Reviews, 35(4), 1042-1051. https://doi.org/10.1016/j.neubiorev.2010.08.011

Pisanti, R., van der Doef, M., Maes, S., Lazzari, D., \& Bertini, M. (2011). Job characteristics, organizational conditions, and distress/well-being among Italian and Dutch nurses: A cross-national comparison. International Journal of Nursing Studies, 48 48(7), https://doi.org/10.1016/j.ijnurstu.2010.12.006

Podsakoff, P. M., MacKenzie, S. B., Lee, J.-Y., \& Podsakoff, N. P. (2003). Common method biases in behavioral research: A critical review of the literature and recommended remedies. Journal of Applied Psychology, 88(5), 879-903. https://doi.org/10.1037/0021-9010.88.5.879

Rundmo, T. (2000). Safety climate, attitudes and risk perception in Norsk Hydro. Safety Science, 34(1-3), 47-59. https://doi.org/10.1016/S0925-7535(00)00006-0

Sjöberg, L. (1998). Worry and risk perception. Risk analysis, 18(1), 85-93. https://doi.org/10.1111/j.15396924.1998.tb00918.x

Son, H., Lee, W. J., Kim, H. S., Lee, K. S., \& You, M. (2019). Hospital workers' psychological resilience after the 2015 Middle East respiratory syndrome outbreak. Social Behavior and Personality: An international journal, 47(2), 1-13. https://doi.org/10.2224/sbp.7228

Sridhar, S., Brouqui, P., Fontaine, J., Perivier, I., Ruscassier, P., Gautret, P., \& Regner, I. (2016). Risk perceptions of MSF healthcare workers on the recent Ebola epidemic in West Africa. New Microbes and New Infections, 12, 61-68. https://doi.org/10.1016/j.nmni.2016.04.010

Stewart-Taylor, A. J., \& Cherrie, J. W. (1998). Does risk perception affect behaviour and exposure? A pilot study amongst asbestos workers. The Annals of Occupational Hygiene, 42(8), 565-569. https://doi.org/10.1093/annhyg/42.8.565

Sultana, A., Sharma, R., Hossain, M. M., Bhattacharya, S., \& Purohit, N. (2020). Burnout among healthcare providers during COVID-19: Challenges and evidence-based interventions. Indian Journal of Medical Ethics. https://doi.org/10.20529/IJME.2020.73

van de Vijver, F., \& Hambleton, R. K. (1996). Translating tests. European Psychologist, 1(2), 89-99. https://doi.org/10.1027/1016-9040.1.2.89 
Vandenberg, R. J., \& Lance, C. E. (2000). A review and synthesis of the measurement invariance literature: Suggestions, practices, and recommendations for organizational research. Organizational Research Methods, 3(1), 4-70. https://doi.org/10.1177/109442810031002

Wang, J., Zhou, M., \& Liu, F. (2020). Reasons for healthcare workers becoming infected with novel coronavirus disease 2019 (COVID-19) in China. Journal of Hospital Infection, 105(1), 1-2. https://doi.org/10.1016/j.jhin.2020.03.002

World Health Organization. (2020). Timeline: WHO's COVID-19 response. https://www.who.int/emergencies/diseases/novel-coronavirus-2019/interactive-timeline

$\begin{array}{ll}\text { Historial do artigo } & \\ \text { Recebido } & 08 / 2020 \\ \text { Aceite } & 01 / 2021 \\ \text { Publicado online } & 03 / 2021 \\ \text { Publicado } & 06 / 2021\end{array}$

